\title{
Comparison of RSM and RA with ANN in predicting mechanical properties of friction stir welded aluminum pipes
}

\author{
IBRAHEEM SABRY, AHMED M. EL-KASSAS, A.M. KHOURSHID AND H.M. HINDAWY
}

\begin{abstract}
Aluminum can't successfully be arc welded in an air environment, due to the affinity for oxygen. If fusion welded in normal atmosphere oxidization readily happens and this outcome in both slag inclusion and porosity in the weld, greatly reducing its mechanical properties. This work presents a systematic approach to develop the suggestion model by three (ANN), response surface methodology (RSM) and regression analysis (RA) for predicting the ultimate tensile strength, percentage of elongation and hardness of 6061 aluminum alloy which is widely used in automotive, aircraft and defense industries by incorporating (FSW) friction stir welding process parameter such as tool rotation speed, welding speed and material thickness. The results obtained through regression analysis and response surface methodology were compared with those through artificial neural networks.
\end{abstract}

KEY WORDS : Friction stir welding, Aluminium pipe, Regression analysis, Response surface methodology, Artificial neural network

How to cite this Article : Ibraheem Sabry, Ahmed M. El-Kassas, A.M. Khourshid and H.M. Hindawy, (2017). Comparison of RSM and RA with ANN in predicting mechanical properties of friction stir welded aluminum pipes. Engg. \& Tech. in India, 8 (1\&2) : 1-14; DOI : 10.15740/ HAS/ETI/8.1\&2/1-14. 